\title{
Changes and Impacts of Heritage Building to Small Hotel Building: A Case Study of Bangkok Story Hostel
}

\author{
Chotewit Pongsermpol ${ }^{1} \&$ Prapatpong Upala $^{1}$ \\ ${ }^{1}$ Faculty of Architecture, King Mongkut's Institute of Technology Ladkrabang (KMITL), Bangkok, Thailand \\ Correspondence: Chotewit Pongsermpol. Tel: 6681-551-3544. E-mail: chotewit@hotmail.com
}

Received: October 1, $2017 \quad$ Accepted: November 18, $2017 \quad$ Online Published: December 27, 2017

doi:10.5539/ass.v14n1p79 URL: https://doi.org/10.5539/ass.v14n1p79

\begin{abstract}
Over the last decade, trends of adaptive reuse of old buildings turned into hotels have been popular in Thailand, especially in Bangkok. Adaptive Reuse Heritage Building converted to the Hotel Building, AR-HB-hotel, effects changes and impacts in several aspects. There have been established criteria for substantial renovation, business investment and assessment of the value of heritage buildings but no concern has been paid to the surrounding community impact. The objective is to study four issues of AR-HB-hotel focused on (1) physical, (2) economic, (3) value changes, and (4) social impacts. The research method is qualitative approach with case study type. 'Bangkok Story Hostel' was selected as a representative case for AR-HB-hotel. This small 3-storey heritage hotel is located in a traditional trading district on Songward Street, Sampanthawong district, Bangkok. For the data collection, building history and project background, as well as physical and economic changes were collected from secondary data, surveys, and in-depth interview. Value change and social impact were collected from in-depth interview and questionnaire. The results showed that the level of physical, economic, and value changes of this building rose up, while the level of social impact stays the same or decreased a little less than the level before the renovation. This research may not be generalized wholly to another case with a significantly different context, but the four main approaches for examining physical, economic, value, and social issues and the procedure used in this study can be a guideline for future studies of AR-HB-hotel' changes and impacts.
\end{abstract}

Keywords: adaptive reuse, heritage building, changes, impacts, Bangkok Story Hostel

\section{Introduction}

An adaptively reuse project or conversion is a means to facilitate a major reuse of buildings (Remoy, 2014). Main issues associated with adaptive reuse of buildings are such as financial, environmental, and social issues as mentioned in ARP (Adaptive Reuse Potential) (Langston, 2008). As heritage buildings are worth preserving, their value is one significant issue that we have to consider. Heritage is valued in a variety of ways and the value is driven by different motivations: economic, political, cultural, spiritual, aesthetic, e.g. (Avrami et al., 2000). In particular for old heritage buildings, this is a significant conservation method that can preserve their architectural heritage at a time of rapid development. Adaptive Reuse (AR) method is the only architectural heritage preservation approach that addresses all three mains issues of sustainable development: the environment, economy, and society or cultural (Giddings, 2002; Naseer, 2003). It can be considered as conciliation between historical preservation and demolition.

AR of heritage buildings has several patterns according to functional usages: palaces or old houses adapted into office buildings, old houses converted into museums, restaurants, boutique hotels as well as shops, various other kinds of buildings changed to museums including commercial buildings whose original interior function turned into various other kinds of functions (Pongsermpol, 2011). For this study, we focused on one kind of adaptive reuse: building converted to Hotel Building (AR-hotels). Over the last decade, the trend of adaptive reuse of old buildings to hotels (AR-hotels) has been very strong in Thailand, especially in Bangkok.

In the case of Adaptive Reuse Heritage Building converted to the Hotel Building, AR-HB-hotel, there have been many standards for physical renovation, business investment, and heritage building evaluation (Pongsermpol \& Upala, 2017). Started with (1) the substantial renovation, there were architectural and interior standards applicable to small hotel design, e.g., a small hotel had to have four main distinct types of areas: guest room, public area, administration office and 'back-of-house' facility (Pickard, 2002). (2) Regarding business investment, there are five main issues in small hotel business operation: service design, operation, sales and marketing, finance and accounting as well as management (Suksawasdi, 2015). To end with (3) heritage building evaluation, there have been some standards regarding heritage value and authenticity such as cultural and socio-economic value including regarding 
authenticity - form and design, materials and substance, use and function, traditions, techniques and management systems, location and setting, language and other forms of intangible heritage, spirit and feeling, and other internal and external factors (WHC, 2012). In addition, (4) regarding social impacts to the surrounding community, there have not been many studies in the literature despite their significance. The social impacts focused on tourism could be perceived as positive, negative, or neutral. Each individual case can exhibit results that are much different from other cases (Pongsermpol \& Upala, 2017). Therefore, AR-hotel projects have always resulted in changes of physical, economic, and value aspects as well as social impacts on the surrounding communities, so this study kept the focus on these 4 main issues: physical, economic, and value changes as well as social impacts as shown in Figure 1.

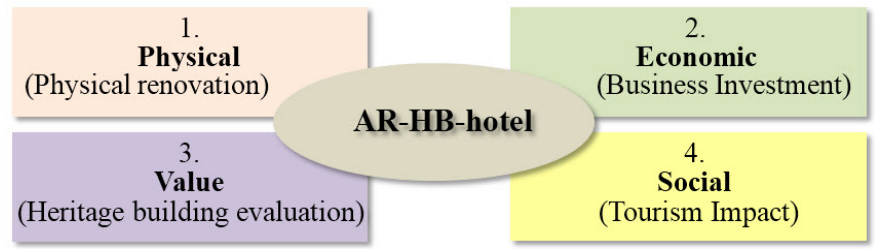

Figure 1. Four main issues of the study

In the target areas in Bangkok, there were many AR-hotels spread throughout, especially in the inner zone. The trend of this phenomenon is increasing continuously into the near future. Basically, there are five main reasons why adaptive reuses of heritage houses or buildings to hotel buildings (AR-HB-hotel) were very popular in Bangkok (Pongsermpol \& Upala, 2017). They were (1) the increased awareness of heritage conservation, (2) the enactment of Hotel Act-2008, (3) the rapid communication through modern information technology, (4) the development of wide-coverage public transport network, and (5) the easy access of members from ASEAN Economics Community (AEC). At the time of this study, there were a large number of old buildings adapted to hotel buildings (AR-hotel) distributed all around in Bangkok.

In a preliminary investigation, thirty-two AR-HB-hotels were investigated in total (Pongsermpol, 2017). After some consideration, eight cases were selected for study according to the criteria of outstanding and unique character to the surrounding community. These cases were Here Hostel, The Bhuthorn Bed \& Breakfast, Arun Residence, New Phiman Riverview Guesthouse, Bangkok Story Hostel, Praya Palazzo, Siamotif Boutique, and Si Yaek Huatakhe Cafe \& Guesthouse. With a deeper consideration for mixed qualitative and quantitative study, Bangkok Story Hostel was selected for this investigation. The reasons for this selection was that Bangkok Story Hostel was in the inner Bangkok area; it was a good representative that was situated in a mixed-use community; the community was an old, outstanding historical trading community; the hostel was small but had a high bed capacity; and the building owner gave us full cooperation.

The objectives of this mixed study are (1) to investigate the physical, economic (Langston, 2008), and value (Avrami et al., 2000) changes that occurred after an adaptive reuse of 'Bangkok Story Hostel' building and (2) to examine the social impacts on its surrounding community. As for the scope of the study, we chose only this over-50-year-old building and only considered the changes from the last function of the building to the current function of a hotel although the building had been used for many functions before.

This paper comprises six sections of content included: (1) Introduction which explains the background, phenomenon concerned to AR-HB-hotel, research gap, and target area; (2) Literature review which studies on definitions and four main approaches - physical, economic, and value changes as well as social impact-associated with the small AR-HB-hotel including research framework; (3) Research methodology which explains target case study, issues of concern, research tools, data collection, and mixed qualitative and quantitative method; (4) Research results which are separated into five sections, general information on 'Bangkok Story Hostel', physical change, economic change, value change, and social impact; (5) discussion which explains analyze the results in the overview, and result guideline; and (6) research conclusion.

Nomenclature

AR: $\quad$ Adaptive Reuse

AR-hotel: $\quad$ Adaptively Reused Hotel from an old building

AR-HB-hotel: Adaptively Reused Hotel from a Heritage Building

\section{Literature Review}

In this section are definitions and four main approaches-physical, economic, and value changes as well as social 
impact - associated with the small AR-HB-hotel. They were guidelines for our studying of changes and impacts that occurred after an AR-HB-hotel named 'Bangkok Story Hostel' came into operation. The following are our application of these approaches.

Firstly, 'Hotel' means a place of temporary serviced accommodation with fee charged excluding non-profit government accommodation and monthly serviced accommodation (Policy Research for SMEs, 2004), and an accommodation that has the total number of the rooms in one or more buildings of more than 4 and can accommodate more than 20 people (Ministerial Regulation, 2008). 'Small hotel' is a currently and widely used term in small hotel business or small and medium-sized hotel enterprises (SMEs). Small hotels can have different numbers of room such as less than 60 rooms (National Statistical Office, 2014), less than 100 rooms (Grey and Liquori, 2004 in Suksuthi, 2015), and less than 50 rooms (Ministerial Regulation, 2008). Here in this paper, small hotel means hotel where has a number of rooms of less than 50. 'Small hotel type' is classified according to the hotel business characteristics and management such as a boutique hotel (Choochote, 2014), guest house, home stay, budget hotel, hostel, and so on. For this case, 'Bangkok Story Hostel' is considered the small hotel in terms of hotel business and marketing but legally, it was a temporary shelter that charged a fee for a stay. This hotel was a boutique hotel which was compact in size with the unique style; it was also a budget hotel (Jones, 2002) with shared bedrooms and bathrooms; it can also be considered a hostel since it had a small common area on the first floor as well.

Secondly, according to the physical change approach focused on building renovation, there were architectural and interior design standards that were applicable to small hotel design, e.g., a small hotel had to have four main distinct types of areas: guest room, public area, administration office and 'back-of-house' facility (Pickard, 2002). In comparing physical changes, there were five main issues to consider (Langston et al., 2010): (1) the building's structural strength - pile system, column, beam, floor, and roof frame (Srisompong, 2004) ; (2) the building's architectural condition-wall, ceiling, finishing, door and window, sanitary-ware, stucco, and decoration systems (Sthapitanonda, 2011); (3) the various building systems - electrical, water supply, drainage, water treatment, air-conditioning, and fire protection systems (Sthapitanonda, 2011; Thirakamen, 2009); (4) the interior conditions - built-in furniture, movable furniture, appliances, and decoration; and (5) the conditions of the exterior and the surroundings - landscape, plants, and fence.

Thirdly, according to the economic change approach focused on small hotel business, there were five main issues concerning small hotel business operation: service design, operation, sales and marketing, finance and accounting as well as management (Somsawasdi, 2015). In comparing economic change involving AR-HB-hotels, there were five main economic issues to consider: (1) building price or financial investments (Dzhandzhugazova et al., 2017), (2) exact operational cost per month, (3) average income per month, (4) owner's satisfaction, and (5) consumers' rating score or tourist satisfaction (Choochote, 2014).

Fourthly, according to the value change approach focused on heritage value, there were two main types of value - cultural and socio- economic values - detailedly expressed as identity, artistry, rarity, functional, economic, educational, social, and political values (Jokilehto, 1998). Authenticity is significant in evaluation of cultural heritage which UNESCO has used as a criterion for world heritage - form and design, material and substance, use and function, traditions - techniques and management systems, location and setting, language and other forms of intangible heritage, spirit and feeling, and other internal and external factors (WHC, 2012). In comparing the value change in AR-HB-hotels, there were five main issues to consider: (1) value of cultural heritage identity - uniqueness, pride of ownership (Khanjanusthiti, 2009; WHC, 2012) (2) design value-form, structural technique, functional concept, and craftsmanship (Jokilehto, 1998); (3) aesthetic value; (4) cultural value and -reflection of the local way of life (ICOMOS, 1994; Jeungsiriarrak, 2005); and (5) an integrated view of all values.

And lastly, according to the social impact approach focused on tourism impact, there were several key independent variables that influence attitudes toward tourism (Lankford \& Howard, 1994). Although tourism causes a positive economic outcome, it can exert negative impacts on the socio-cultural, economic, environmental and political development of the destination country (UNEP, 2003; Mohammadi et al., 2010) as well depending on the way that they are managed. In our study of social impact on the communities surrounding AR-HB-hotels, five main issues were considered: (1) environmental impact and pollutions - noise, odor, daylight, air flow through the block, traffic condition, and population density; (2) community economic development-income from tourism, income from other means; (3) stakeholders' relationship - community interaction, and participation (Polnyotee, 2015); (4) privacy impact - original way of life, serenity, reputation to outsiders (Altman, 1975) ; and (5) security impact focused on danger that may happen - robbery, crime, and encounter with strangers (Jeffery, 1971; Bynum \& Purri, 1984).

The constructed procedure from these 4 main approaches can be a good general guideline for constructing a new research procedure for other studies of AR-HB-hotels' changes and impacts. The overview of our usage of these four 
approaches is illustrated in the flow chart below as shown in Figure 2.
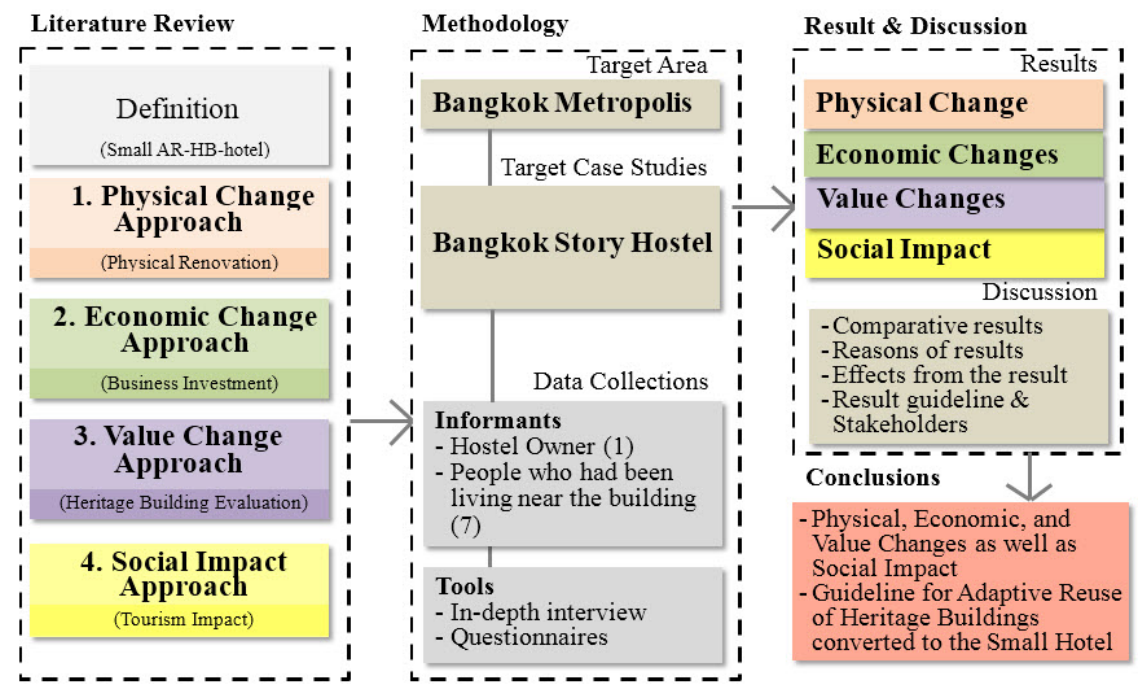

Figure 2. Research Process Framework

\section{Research Methodology}

The study focused on one representative case, Bangkok Story Hostel and used data collection methodology constructed according to the four main issues of concern.

\subsection{Target Case study}

'Bangkok Story Hostel' was located in the old downtown, Sampantawong district, Bangkok metropolis (see Figure.3). It was a representative of AR-HB-hotel cases that was situated in a historical commercial area named 'Chiang Kong' in Talaad Noi community. It was a widely-known trading area of used metal, auto spare parts, and other mechanical engine parts.

\subsection{Issues of concern}

Four main issues were in focus in this study of changes and impacts: (1) Physical change-building's structural strength, building's architectural condition, various building systems, interior conditions, and conditions of the exterior and the surroundings; (2) Economic change-building price, exact operational cost per month, average income per month, owner's satisfaction score, and overall score from consumers' rating; (3) Value change—value of cultural heritage identity, design value, aesthetic value, cultural value, and an integrated view of all values; and (4) Social impact on surrounding community - environmental community, economic development, stakeholders' relationship, privacy and Security. All the concerned issues and sub-issues are shown in Table 1.

Table 1. Four main approaches, issues of concern, and sub-issues

\begin{tabular}{|c|c|c|c|}
\hline Code & Approach & Issues of concern & Description \\
\hline \multirow{5}{*}{$P$} & \multirow{5}{*}{$\begin{array}{l}\text { Physical } \\
\text { Change }\end{array}$} & $\begin{array}{l}\text { P01:Building's structural } \\
\text { strength }\end{array}$ & Pile system, Column, Beam, Floor, and Roof framing \\
\hline & & $\begin{array}{l}\text { P02: Building's architectural } \\
\text { condition }\end{array}$ & $\begin{array}{l}\text { Wall system, Ceiling, Finishing, Door/Window, Sanitary-ware, and } \\
\text { stucco and decoration system }\end{array}$ \\
\hline & & P03: Various building systems & $\begin{array}{l}\text { Electrical, Water supply, Drainage, Water treatment, } \\
\text { Air-conditioning, and Fire protection systems }\end{array}$ \\
\hline & & P04: Interior conditions & Built-in furniture, Movable furniture, and appliance and decoration \\
\hline & & $\begin{array}{c}\text { P05: Conditions of the exterior } \\
\text { and the surroundings }\end{array}$ & Landscape, plants, and fence \\
\hline \multirow{3}{*}{$\mathrm{E}$} & \multirow{3}{*}{$\begin{array}{l}\text { Economic } \\
\text { Change }\end{array}$} & E01: Building price & Estimated building value \\
\hline & & $\begin{array}{l}\text { E02: Exact operational cost } \\
\text { per month }\end{array}$ & $\begin{array}{l}\text { Estimated building improvement expenses such as for structural } \\
\text { work, building work, interior work, and mechanical system work }\end{array}$ \\
\hline & & $\begin{array}{l}\text { E03: Average income per } \\
\text { month }\end{array}$ & $\begin{array}{l}\text { Average income per month assessed from hotel operation with } \\
\text { deducted operational expenses }\end{array}$ \\
\hline
\end{tabular}




\begin{tabular}{|c|c|c|c|}
\hline & & $\begin{array}{l}\text { E04: Owner's satisfaction } \\
\text { score }\end{array}$ & Level of satisfaction toward the income from hotel operation \\
\hline & & $\begin{array}{r}\text { E05: Overall score from } \\
\text { consumers' rating }\end{array}$ & Level of satisfaction scored by on-line visitors \\
\hline \multirow{5}{*}{$\mathrm{V}$} & \multirow{5}{*}{$\begin{array}{l}\text { Value } \\
\text { Change }\end{array}$} & $\begin{array}{l}\text { V01: Value of cultural heritage } \\
\text { identity }\end{array}$ & $\begin{array}{l}\text { Value that reflected uniqueness, pride of ownership of the } \\
\text { architectural heritage that was worth preserving }\end{array}$ \\
\hline & & V02: Design value & $\begin{array}{l}\text { Value that reflected architectural design principles and heritage } \\
\text { including form, structural technique, functional concept, and } \\
\text { craftsmanship }\end{array}$ \\
\hline & & V03: Aesthetic value & Beauty with highly-valued arts and architecture \\
\hline & & V04: Cultural value & Value reflect the ways of life and traditions of the local community \\
\hline & & $\begin{array}{c}\text { V05: Integrated view of all } \\
\text { values }\end{array}$ & High architectural integrity \\
\hline \multirow{5}{*}{$\mathrm{S}$} & \multirow{5}{*}{$\begin{array}{l}\text { Social } \\
\text { Impact }\end{array}$} & $\begin{array}{c}\text { S01: Environmental impact } \\
\text { and pollutions }\end{array}$ & $\begin{array}{l}\text { Noise, Odor, Daylight, Air flow though the block, Traffic condition, } \\
\text { and population density }\end{array}$ \\
\hline & & $\begin{array}{c}\text { S02: Community economic } \\
\text { development }\end{array}$ & Income from tourism, and Income from other means \\
\hline & & $\begin{array}{l}\text { S03: Stakeholders' } \\
\quad \text { relationship }\end{array}$ & Community interaction, and Participation \\
\hline & & S04: Privacy & Original way of life, Serenity, and reputation to outsiders \\
\hline & & S05: Security (Danger) & Robbery, Crime, and Encounter with Strangers \\
\hline
\end{tabular}

\subsection{Research tools}

Being a qualitative study, the data on physical and surrounding changes, as well as on economic changes were collected from the survey, observation, and in-depth interview with the building owner. The data on value changes were obtained by questionnaires from building owner and seven informants from the surrounding community while the data on social impact were gathered and analyzed from informants in the surrounding community as well. Moreover, digital camera, sound recorder, and interview guideline form were used as tools for data collection. A gratuity gift was offered to each participated building owner and informant.

\subsection{Data collection}

There were two main steps in data collection. (1) In the pilot survey, the first round of in-depth interviews with the building owner and seven informants from the community surrounding Bangkok Story Hostel was in November 2016. (2) For the final stage of data collection, the in-depth survey and the second interviews were performed in April 2017. The interview guideline form for the building owner and informants was adjusted from that used in the pilot study so that it was easier to understand and suitable for differentiation of changes between the past and the present. Photos of the atmosphere of the interviews are shown in Figure 4. The collected data were results of site analysis-location, accessibility, sun path and wind direction, and characteristics of the surrounding buildings as well as floor plans of Bangkok Story Hostel.

\subsection{Qualitative method}

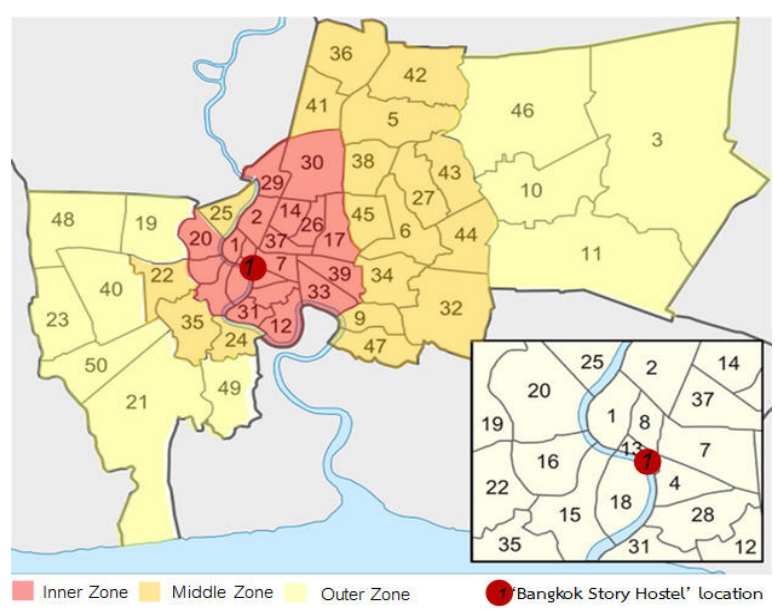

Figure 3. Location of 'Bangkok Story Hostel'

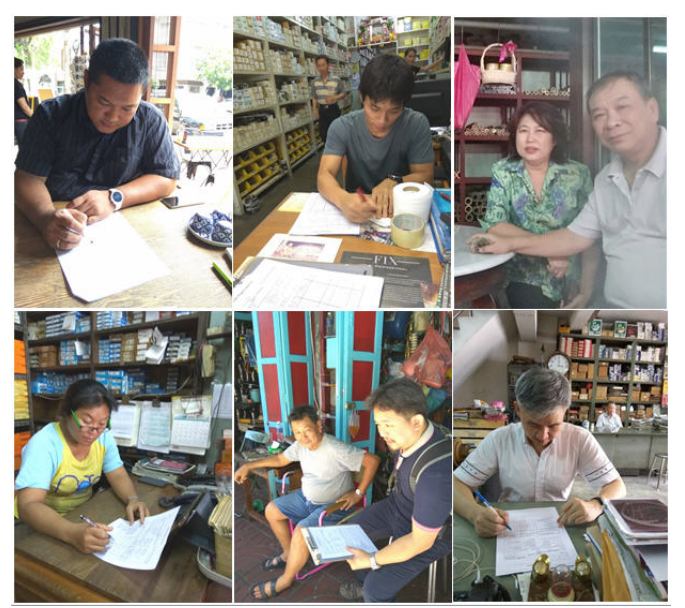

Figure 4. Atmosphere of interview activities 
For describing background information, phenomenon, and building details, qualitative methodology—secondary data collection, surveys, and in-depth interview-was used. For assessing the level of changes and impacts from AR-HB-hotels, Bangkok Story Hostel, questionnaires with Likert scale were used.

\section{Results}

\subsection{General information on 'Bangkok Story Hostel'}

(1) Building History and Project Background

'Bangkok Story Hostel' is a small 3-storey hotel, adapted from an over-100-year-old colonial heritage building. This hostel is located in a traditional trading district on Songward Street, Sampanthawong district, Bangkok. This trading district called 'Chiang Kong' was consisted of shops that sold automobile parts and other mechanical engine parts. This converted building had also been an automobile part shop then converted to a franchised mini-mart under the brand 'Fresh Mart', but afterwards it was left vacant for a period of time before gotten converted again into the 'Bangkok Story Hostel' at the end of 2015. The inspiration behind the conversion of this heritage building into a small hotel was the love of heritage building of Mr. Sanpop Poolsuwan, a 40-year-old interior designer. He had seen a lot of examples of conversion projects in recent past and decided to rent this old building and renovate it into a small hotel.

The timeline history of this hostel is as follows. Around 2015, Mr. Poolsuwan had surveyed several buildings in the inner Bangkok area such as at Phra Nakorn, Dusit, Sampantawongse districts. He focused on the location, accessibility, and form of the heritage building, and at the end of 2015, he chose this building and converted it into a small hotel. Regarding the business side of the conversion, Mr. Poolsuwan signed a rental contract with the owner of the building in August 2015 then renovated the building for 8 months before the official opening of the hostel in April 2016. The hostel was open for 1 year when it was investigated by the author around March 2017.

(2) Location and the surrounding community

Location: The address of 'Bangkok Story Hostel' was 40-42, Songward Road, Talad Noi Subdistrict, Sampantawongse District, Bangkok. The hostel was a 3-storey row house situated at a corner of Songward Intersection where Soi Charoenpanich started. A map of it and surrounding area are shown in Figure 5. Accessibility: Bangkok Story Hostel was directly accessible by car, public bus (bus \#1), underground train, boat, and foot. The distance to the nearest bus stop was 100 meters; the distance to the nearest underground train station (Mahanakorn underground train, MRT) was 600 meters; and the distance to the nearest pier was 400 meters (the pier was along Chao Phraya River) as shown in Figure 6.

Site analysis in terms of the relationships between the location of the building and sun path, wind direction and surrounding noise were performed. Some of the analysis results which are also illustrated in Figure 7 were the following. The front of the building faced Song Wad Intersection in the northeast direction, so in the afternoon it would not face the sun; consequently, the space in the front of the building would be in the shadow and comfortably functional as a common area during that time.

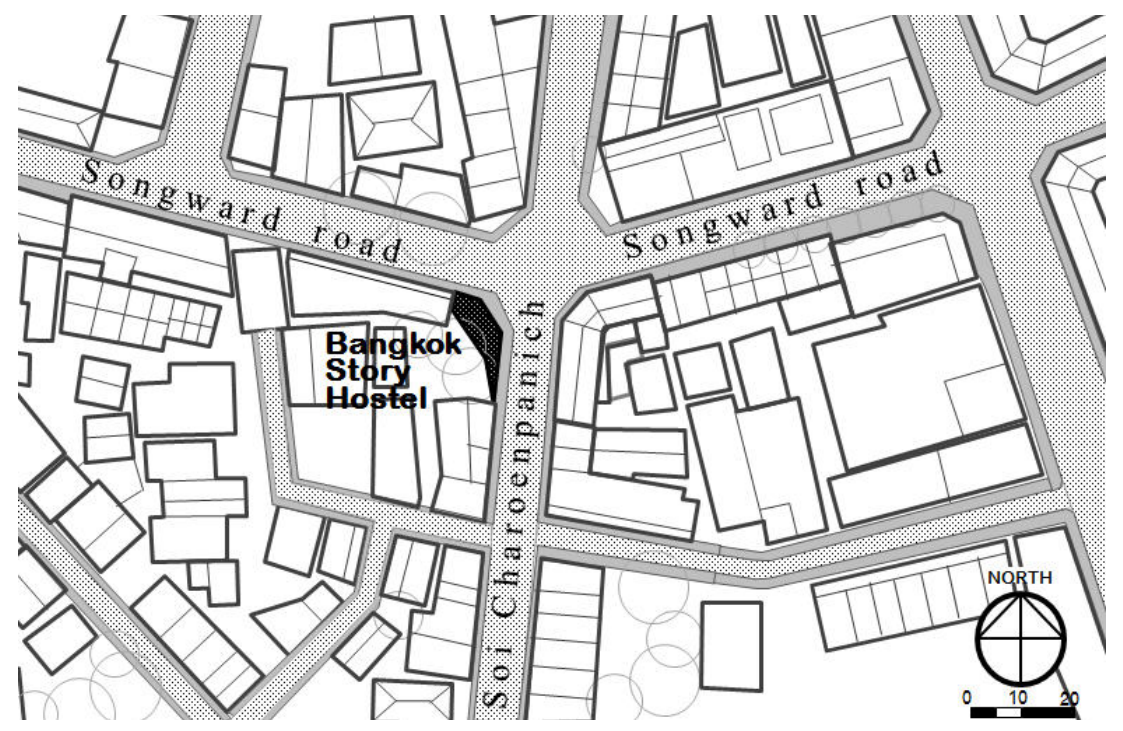

Figure 5. Location map of 'Bangkok Story Building' and surrounding community 


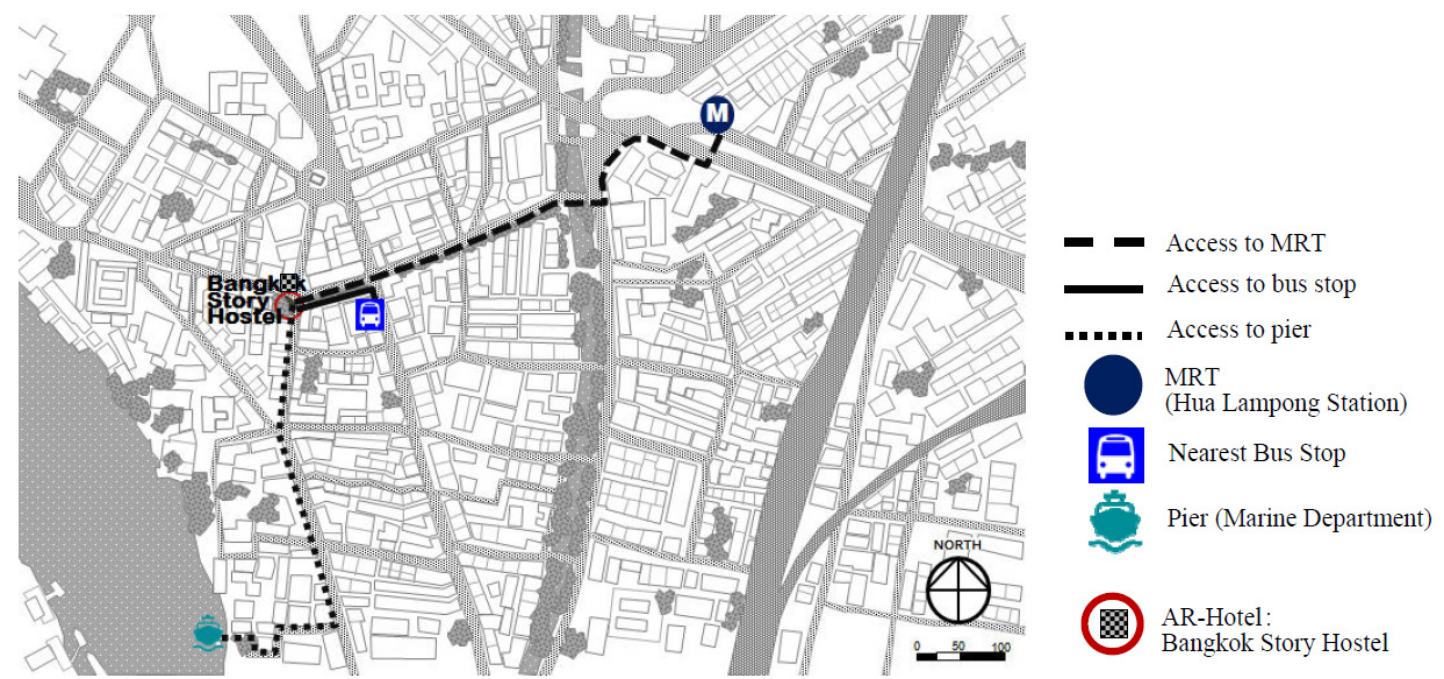

Figure 6. Accessibility map of 'Bangkok Story Hostel'

Regarding wind direction, this location was influenced by the southwest monsoon during summer and the northeast monsoon during winter. The west wall and south corner of the building were opaque masonries and the rooms on the second and third floors were air conditioned, so the wind direction did not have much effect on room usage. However, the common areas on the first (café and reception) and third (shower area) floors would be cooler from the wind during winter.

Regarding surrounding noise, most noises were traffic and community noises coming from Song Wad Road and Soi Charoen Panich in the north and east directions, respectively.

Regarding the type of district, Bangkok Story Hostel was situated in a 100-year-old commercial district of automobile and engine part trade. Most other buildings were row buildings at least 50 years old and of colonial or modern style. Some of which were also deserved to be preserved due to their architectural heritage. Their photos are shown in Figure 8.

\section{(3) Building characteristics}

The Bangkok Story Hostel building was a colonial-style building located at the corner of Songward intersection (see figure 9). Its shape was of an angular water drop. It had a total area of 180 square meters. Each floor had a total area of 60 square meters. The ground floor consisted of a reception area, an office area, a dining area, a storage area, a lavatory, a stair hall, and a water pump room. The second floor consisted of a stair hall, two lavatories, a garden area, and a large 18-bunk-bed bedroom. Lastly, the third floor consisted of a stair hall, a lavatory, a garden area, six shower rooms, five big wash bowls, and a medium-sized 12-bunk-bed bedroom. The floor plans are shown in Figure 10.

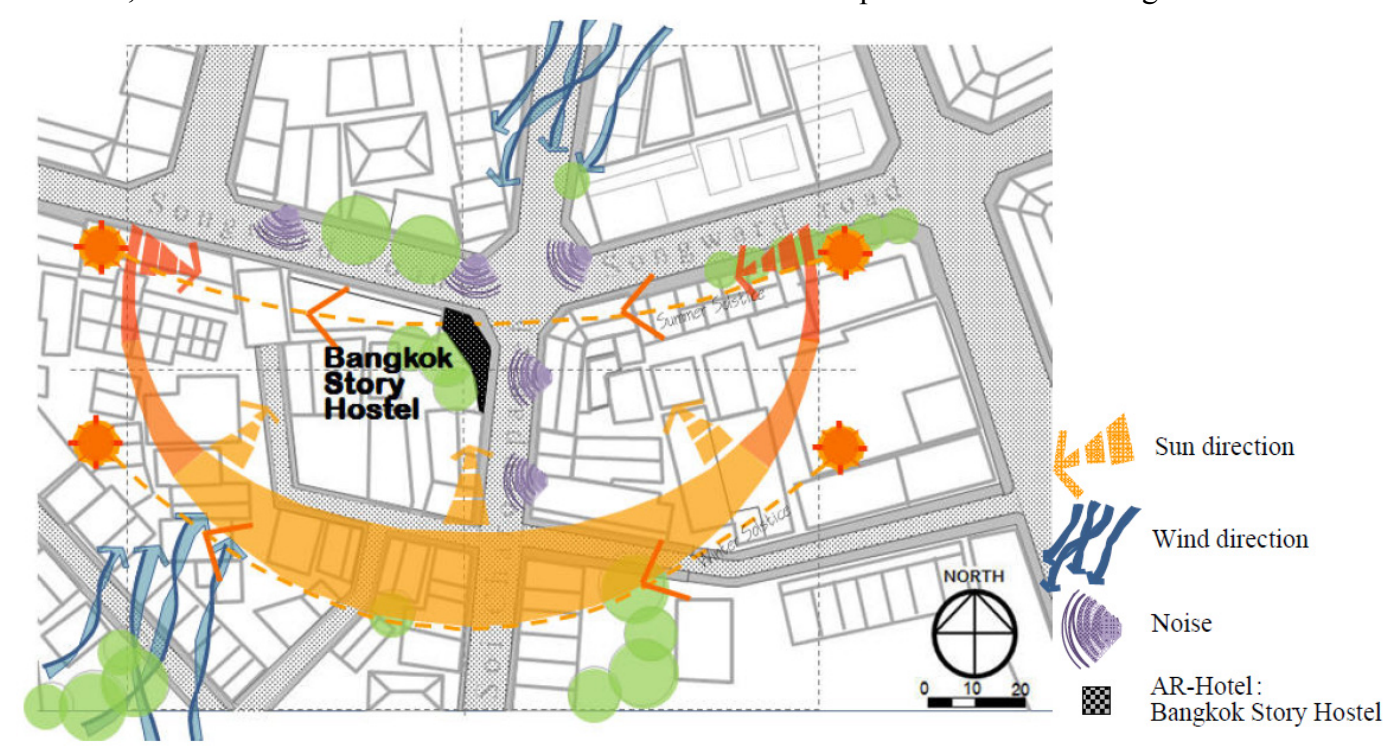

Figure 7. Site analysis map of 'Bangkok Story Hostel' 


\subsection{Physical Change}

For the physical change study, we focused on five sub-issues: (1) building's structural strength, (2) architectural condition, (3) various building systems, (4) interior conditions, and (5) conditions of the exterior and the surroundings. Before having been adapted to a small hotel, the 'Bangkok Story Hostel' building was left vacant for a period of time after it had been used as a mini-mart. The physical condition was in disrepair due to lack of use. As for the building's structural strength, the pile system, column, beam, floor, and concrete deck roof were all in good condition. There was no change in structural strength after renovation. For the building's architectural condition, the former conditions of the brick wall, gypsum board ceiling, and door-window system were moderate and got better after renovation. The former ceiling was demolished in order to build a higher ceiling and the old steel beam was covered with gypsum board to make it look more like a concrete beam. The old aluminum door and windows on the ground floor were totally demolished and timber accordion doors and windows were built in place of it. The former stairs were relocated from the corner triangular space in the south to the middle space and made wider. The stairs' new location allowed more daylight from above. The corner triangular space on each floor was adapted to be a lavatory instead. Interestingly, the concrete deck space on the third floor was adapted to be a shower and wash bowl area connected to a medium-sized 12-bunk-bed bedroom. All of the finishing materials such as floor and wall finishing materials were in dilapidated condition and were improved after the renovation.

On the other hand, the window frames, stucco, and decoration had already been in good condition and were kept intact. Several views of the exterior architecture are shown in Figure 11. As for the various previous building systems, the electrical, air-conditioning, and fire protection systems had been in the worst condition or nonexistent and were improved into a good, very good, and moderate condition, respectively. The moderate condition of the former drainage and water treatment system was improved into a good condition while the bad condition of the water supply system was improved into a good condition as well. As for the interior conditions, all built-in furniture, movable furniture, appliances, and decoration were previously non-existent. They were installed in good condition except the movable furniture was in a moderate condition. Several views of the interior are shown in Figure 12. Lastly, as for the exterior and the surroundings, previous landscape, and plants had been non-existent. They were built or planted and were in moderate condition. A summary with numerical evaluations of the physical changes is shown as a bar chart in Fig 13.
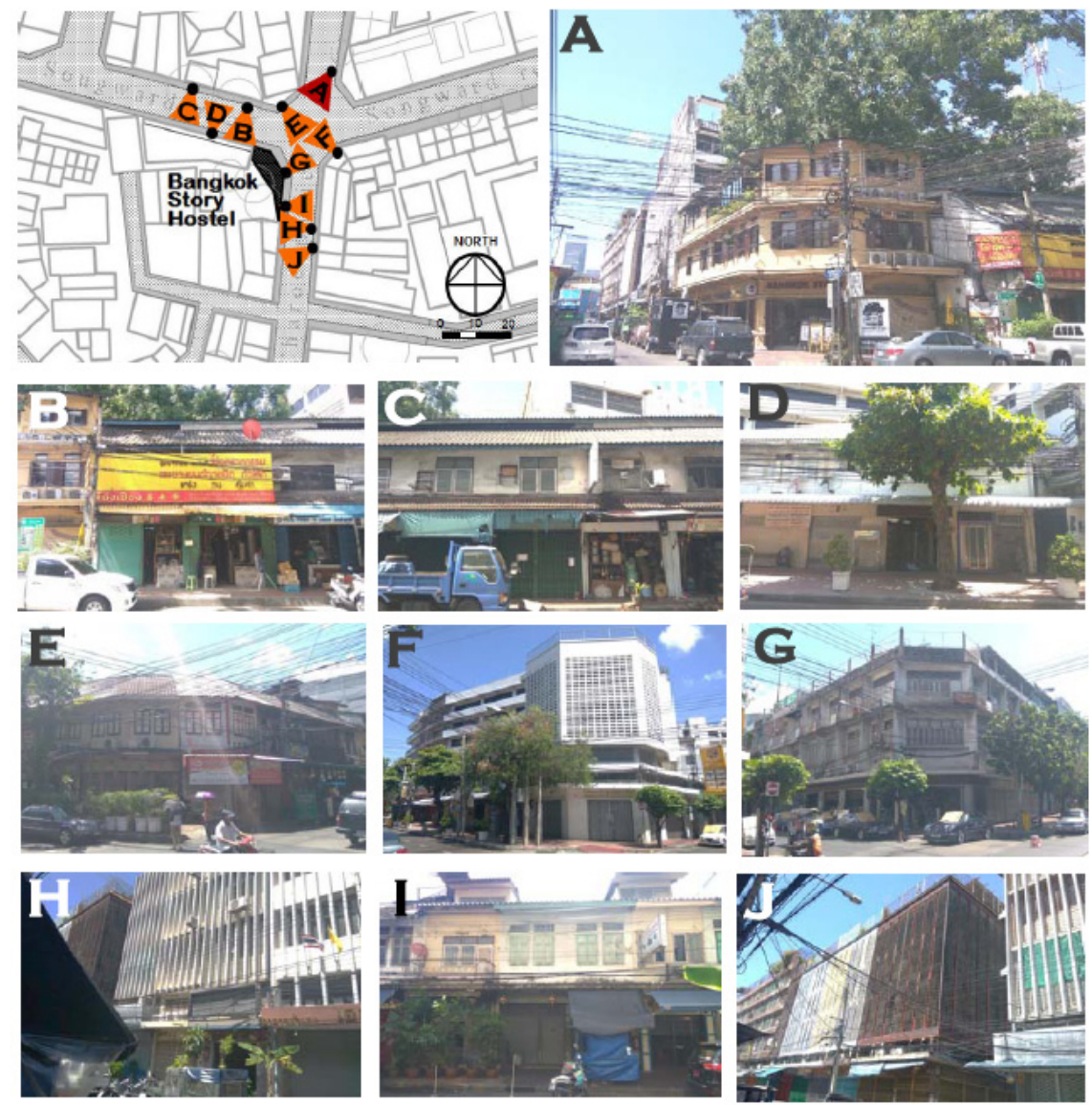

Figure 8. Survey map showing views of the surroundings and the building's exterior 


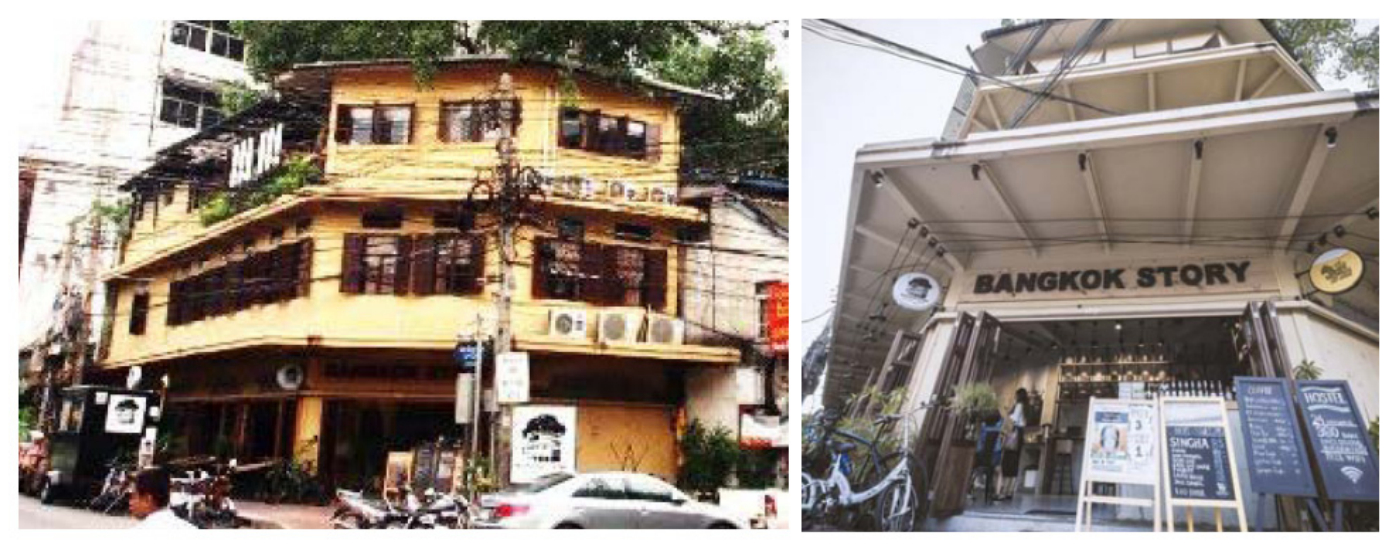

Figure 9. Exterior perspective of Bangkok Story Hostel Building

Source: www.booking.com/hotel/th/bangkok-story.en-gb.html Retrieved 22 Feb. 2017

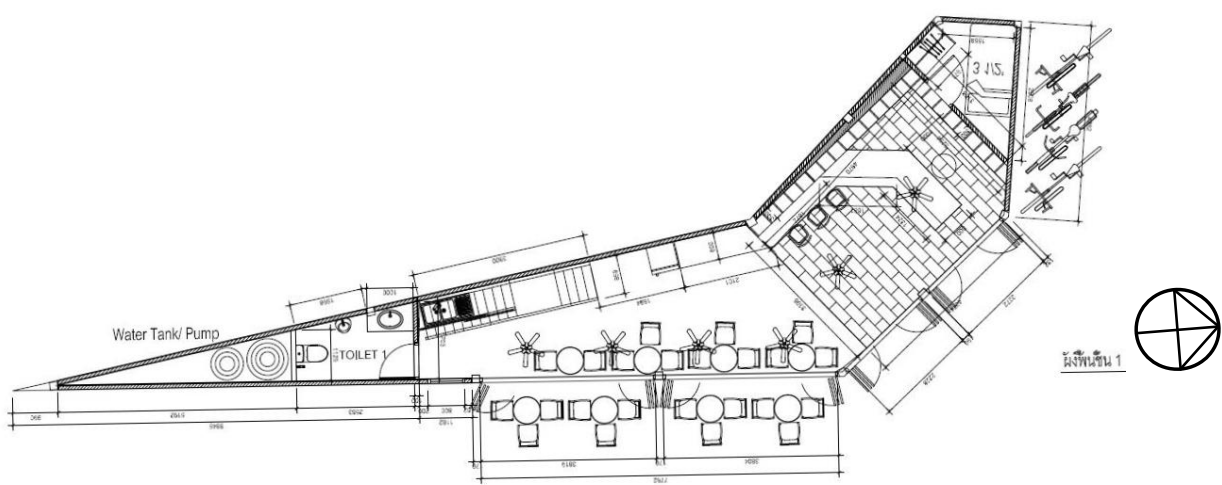

(1) First floor plan

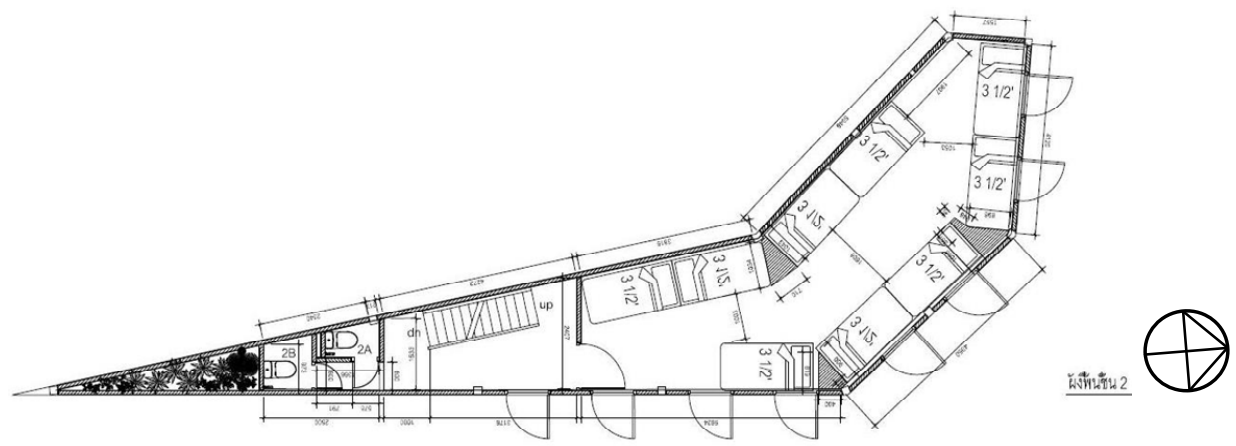

(2) Second floor plan

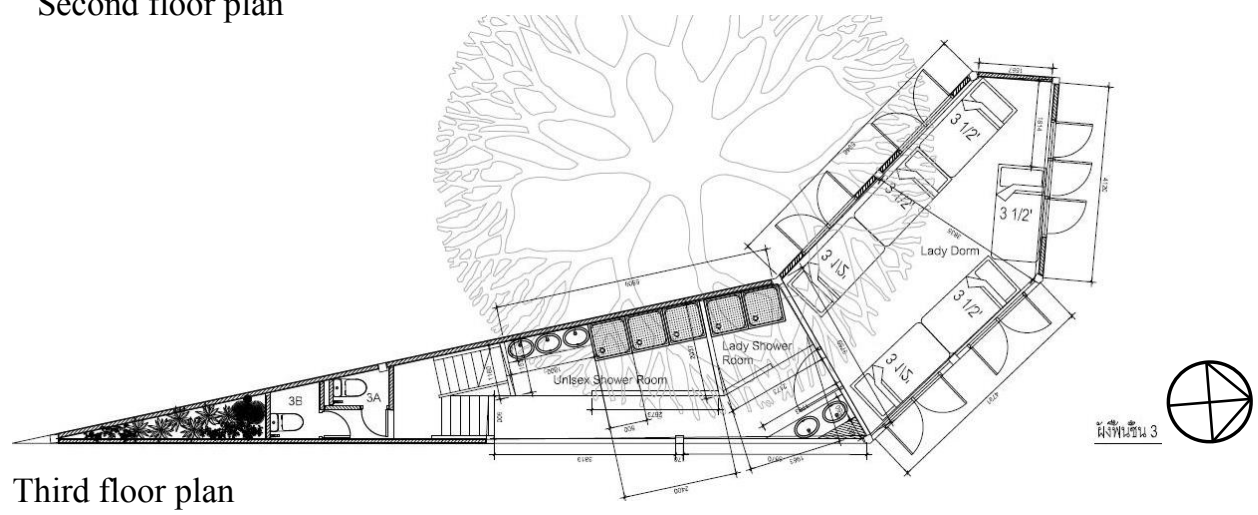

(3) Third floor plan

Figure 10. Draft Floor plan of 'Bangkok Story Hostel' (Photos credited by Mr. Sanpop Poolsuwan) 

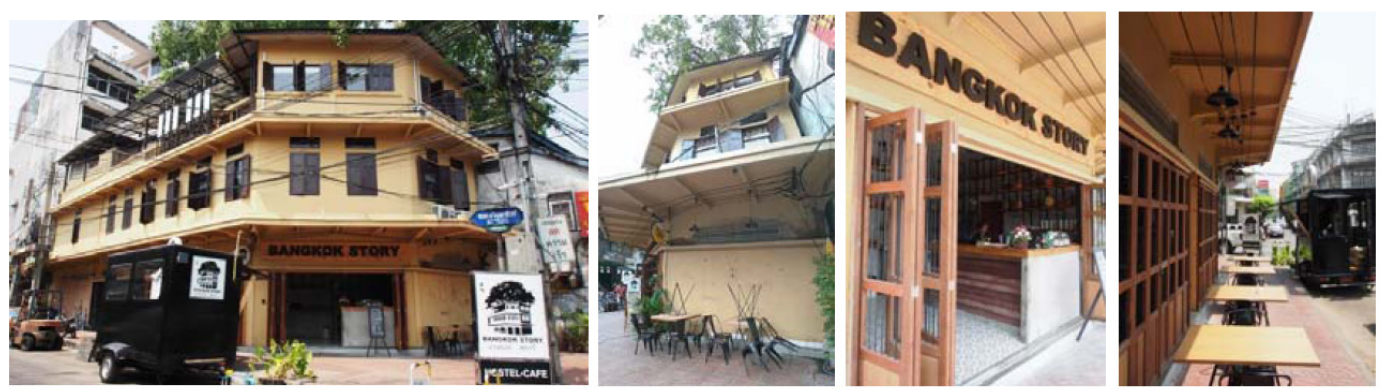

Figure 11. Views of the exterior, decoration, and timber accordion door on the ground floor
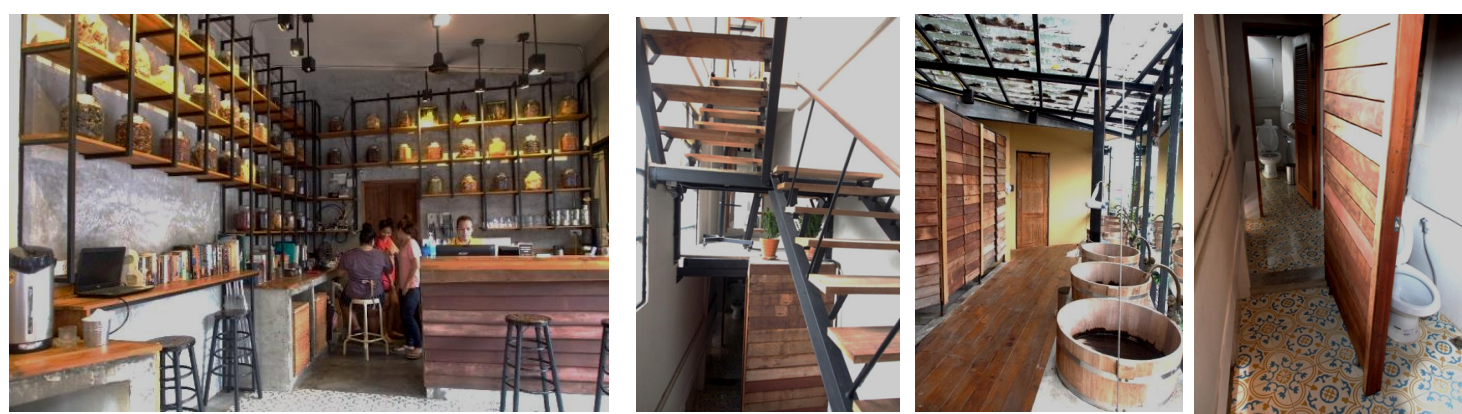

(1) Views of the interior of the welcome hall, stair hall in the middle space, shower area, and lavatories
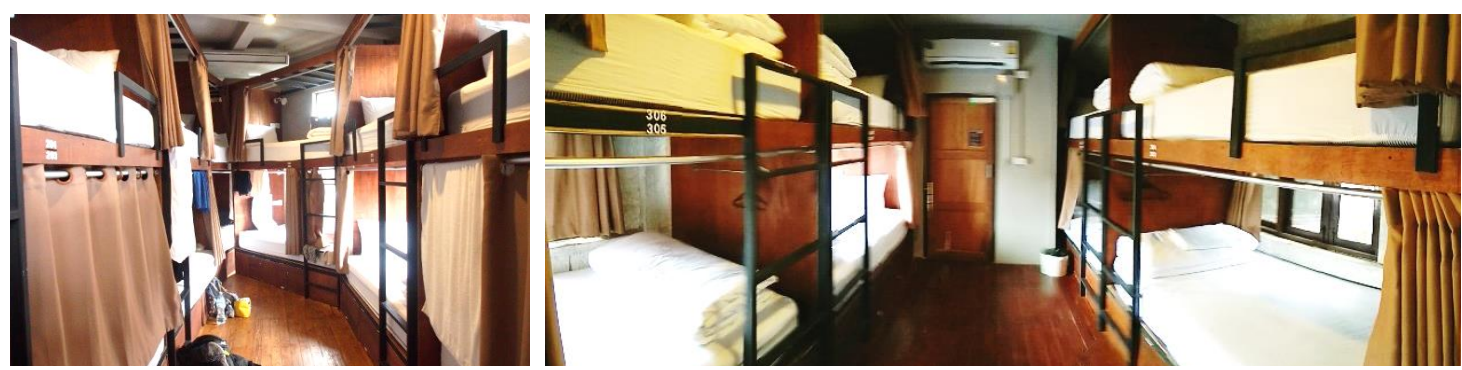

(2) Views of the interior of two shared multi-bunk-bed bedrooms

Figure 12. Views of the interior of Bangkok Story Hostel

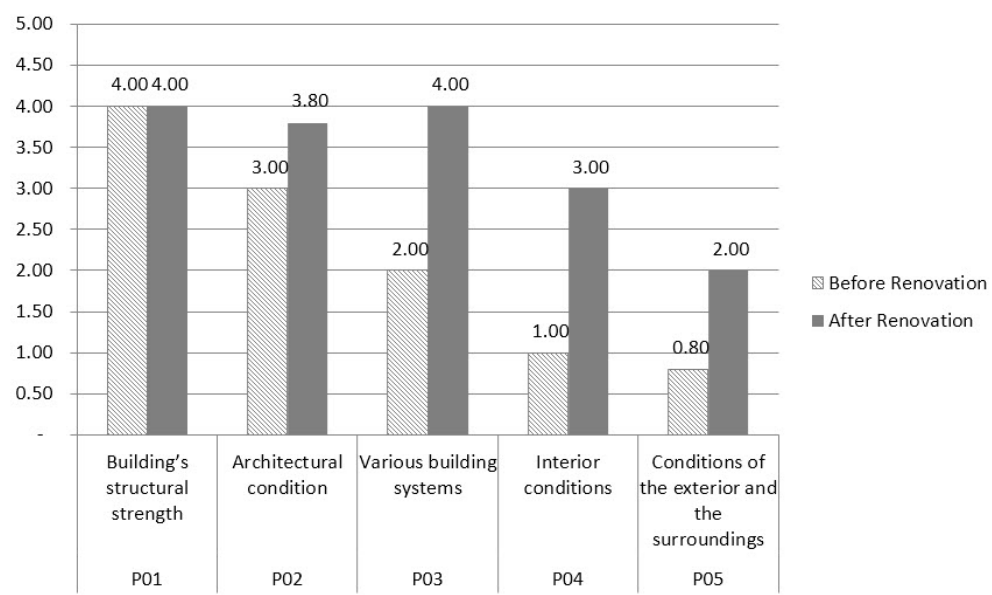

Figure 13. Bar chart of physical change analysis of 'Bangkok Story Hostel'

\subsection{Economic Change}

For the study of economic changes, we focused on five sub-issues that affected hotel owners: (1) building price, (2) exact operational cost per month, (3) average income per month, (4) owner's satisfaction score, and (5) overall score from consumers' rating. From in-depth interviews with the hostel owner, all concerned sub-issues were evaluated with a rating scale of one to five. Cannot-be-revealed raw data regarding hostel investment was collected and compared to those from five other studied cases. The conclusion was that the economic value of Bangkok Story Hostel was at a 
moderate level before the renovation and rose to a high level after the renovation. The exact operational cost per month and average income per month for the formerly vacant building were at the lowest level. After renovation, the exact operational cost per month was at a moderate level while the average income per month was at a high level. The owner's satisfaction level was at a moderate level before renovation and rose up to a high level after that. In addition, the hotel's overall score from consumer's rating (www.booking.com) was between the high and the highest level, much improved from the lowest score when it was a vacant building. A summary of the issues of economic changes is shown as a bar chart in Figure 14.

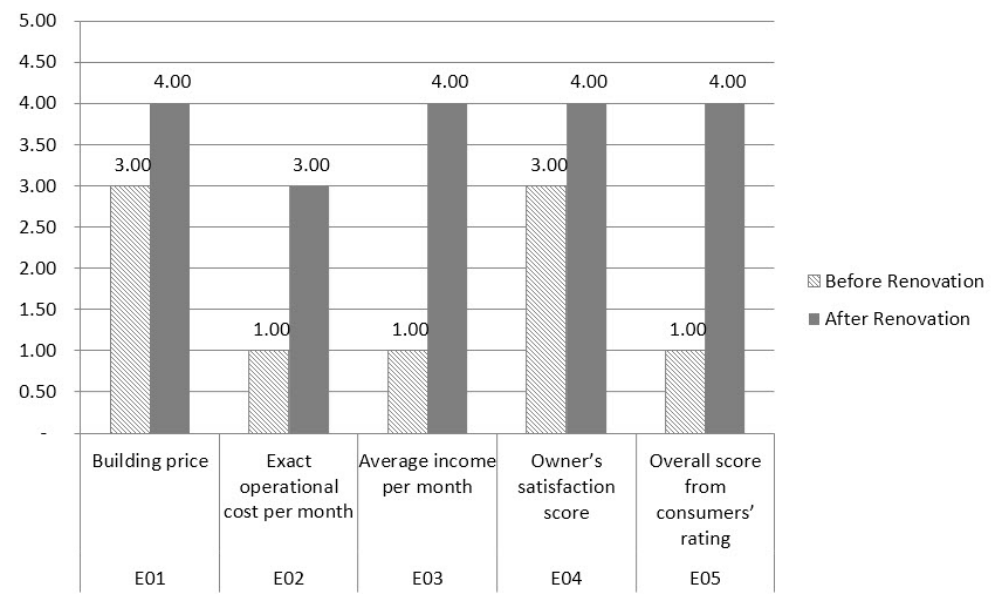

Figure 14. Bar chart of economic change analysis of 'Bangkok Story Hostel'

\subsection{Value Change}

For the study of value changes, we focused on five sub-issues: (1) the value of cultural heritage identity, (2) design value, (3) aesthetic value, (4) cultural value, and (5) an integrated view of all values. From in-depth interviews with the owner and seven informants who had been living near the building, we found that the overall level of perception of the hotel building's value increased almost twice after the building was reused. On the average, almost every perceived value of the former building got a lower score than the perceived value after renovation into a hotel. The perceived values of cultural heritage identity and design rose up to almost double before renovation while the aesthetic value rose up to slightly more than double. However, the new perceived cultural value was only at a moderate level, increased only one and a half times of that before the renovation. The integrated view of all perceived values was at a good level, rose up twice from the value before the renovation. Some interesting details are as follows. The informants paid the most attention to the functional concept, followed by the form of hotel design. They thought that the designer was successful in converting a small dilapidated building into a fully-functional hotel. On the contrary, most informants thought that the hotel still didn't reflect their ways of life and traditions adequately. A summary of the changes in perceived values is shown as a bar chart in Figure 15.

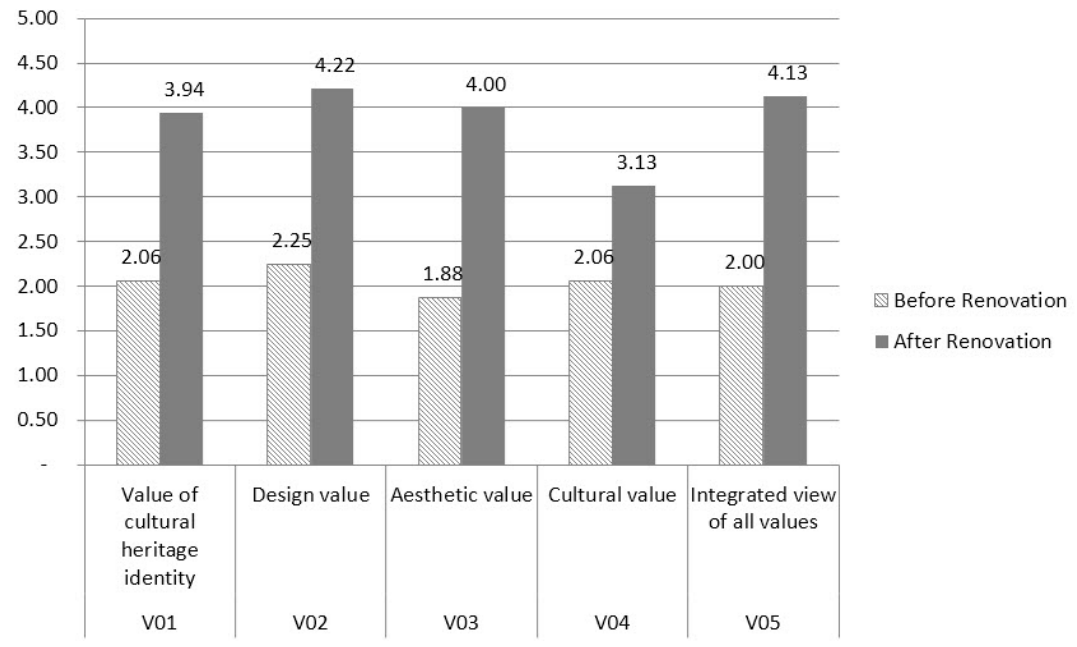

Figure 15. Bar chart of value change analysis of 'Bangkok Story Hostel' 


\subsection{Social Impact}

For the study on social impact, we focused on five sub-issues: (1) environmental impacts and pollutions, (2) community economic development, (3) stakeholders' relationship, (4) privacy impact, and (5) security impact (danger). From in-depth interviews with seven informants who had been living near the building, we found that the overall impact on the community both before and after the AR-HB-hotel project was at a moderate level. On average, the level of each impact was moderate and only slightly different. The before-and-after levels of perceived impact on the environment and pollutions were the same at a low level, while those of stakeholders' relationship were also the same but at a slightly higher level. The AR-HB-hotel made the community' physical environment better, but they did not have much effect on the community's infrastructure. For the level of perceived impact on the community economic development, it was slightly higher than that before the project was done on the average. Apparently, this increase was from the consideration of higher income from tourism development. For the stakeholders' relationship, there was more public social interaction but more than half of the informants expressed a neutral opinion, no positive or negative comments. For the impact on privacy, former lifestyle and tranquility were not affected even though the community became better known to outsiders. The perceived level of impact on security was higher than before shown from the lower level of the possible danger. Some informants thought that the security at night was heightened because of more luminance in front of the AR-HB-hotel. A summary of the perceived social impacts is shown as a bar chart in fig. 16.

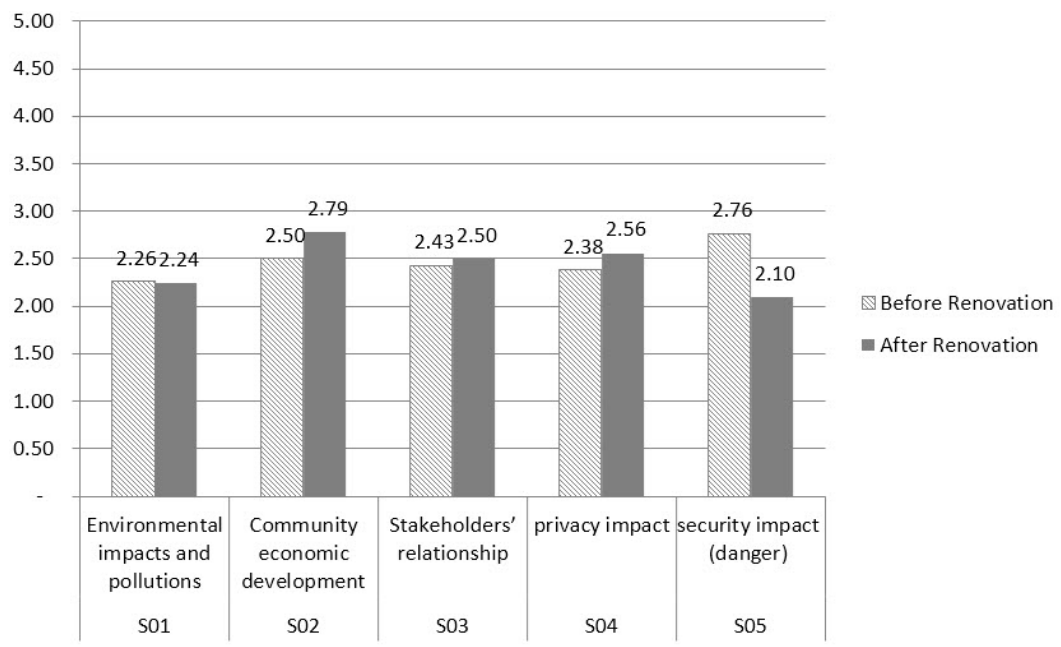

Figure 16. Bar chart of social impact analysis of 'Bangkok Story Hostel'

\section{Discussion}

To understand this research, the procedure for data analysis under this research was set out in 4 parts as follows: part (1) Building description, part (2) Changes and Impacts affected by AR-HB-hotel, part (3) Caused of the results, and part (4) Result guideline.

\subsection{Building description}

'Bangkok Story Hostel' was an interesting heritage building adapted to a small boutique hotel. With the hostel owner's-Mr. Poolsuwan's - awareness in heritage building value and potential renovation, he was able to solve all of the limitations including building size, dilapidated condition, and new hostel function successfully and turned it into a lucrative hostel.

Legally, 'Bangkok Story Hostel' was not considered a hotel because it had fewer than 5 rooms for visitors to stay in even though there were beds for 30. This configuration may conflict with the 2008 Hotel Act that stated that a hotel was an accommodation that had the total number of rooms in one or more buildings of more than 4 and could accommodate more than 20 people. Hence, this hostel was considered a temporary shelter that charged a fee for a stay.

Nevertheless, this project was worth investigating because it was a good case of adaptive reuse of a heritage building that did not make a lot of negative impacts on the surrounding community and should get some support from the state in one way or another.

\subsection{Changes and Impacts affected by AR-HB-hotel}

Referring back to the introduction, our four main investigational approaches were changes in the physical building, economic, and value as well as social impact. For the physical change, we found that the average level of physical change perceived by the owner rose up from a low level (2.16) before renovation to a level between moderate and high 
(3.36) after renovation. The former building's structural strength was in good condition but the levels of architectural condition, various building systems, interior condition, and conditions of the exterior and the surroundings were successively lower. After renovation, the building's structural strength, architectural design, and building systems were perceived to be at a good level, followed by interior conditions at a moderate level, and conditions of the exterior and the surroundings at a low level.

For the economic change, the average perceived level of economic aspect increased from a level between low and moderate (2.60) to a level between moderate and high (3.40). The owner evaluated the former building's economic value and satisfaction at a moderate level while the other sub-issues of economic changes were at the lowest level due to the dilapidated condition. After renovation, the levels of economic changes mostly were at a good level but the exact operational cost per month was at a moderate level.

For the value change, the perceived level of this change altered drastically from the former to the renovated building. The average level of value change increased from a low level (2.05) to an almost high level (3.86). The informants who were the building owner and the people living near the building and recognizing the changes of the building gave priority to the design value the most, followed by the aesthetic value and value of cultural heritage identity.

For the social impact issue, the average levels before and after renovation was almost the same between low and moderate at 2.47 and 2.42, respectively. The social impact affected by this 'Bangkok Story Hostel' trended in a positive direction, especially for the security issue. For example, some informants thought that the security during the night became better because of more luminance in front of the AR-HB-hotel. A summary and assessment of changes and impacts according to the four main approaches are shown in Figure 17.

With respect to the four main approaches, the results from the survey of the AR-HB-hotel named Bangkok Story Hostel showed that the level of physical change rose up a little more than one (1.20) while the level of economic change rose up a little less than one (0.80). Interestingly, the level of value change increased to almost two (1.81) while the level of social impact was at the same level or a little less than before renovation $(-0.05)$.

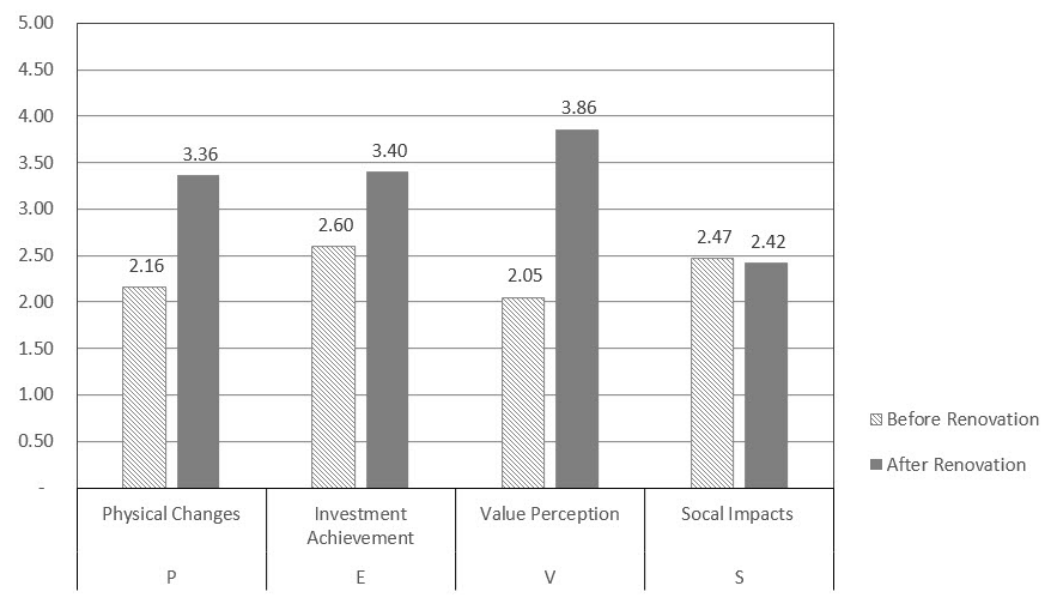

Figure 17. Bar chart of levels of changes and impacts affected by 'Bangkok Story Hostel'

\subsection{Cause of the results}

As mentioned in the introduction, we expected to learn a lot about both the positive and negative social impacts on the community around the AR-HB-hotel, but the results on social impact did not show much negativity. In my point of view, this is a mixed qualitative and quantitative study hence all of the results were contingent upon the specific context of each case such as location, existing building condition, and management including investment; therefore, the results from 'Bangkok Story Hostel' case may not be generalizable to another case with a significantly different context. For example, some case studies in our pilot work heavily affected the communities nearby them. Some former residents who had lived close to a particular hotel were not able to go on signing a rental contract after the hotel was adapted and had to move out unexpectedly from their residence that they had lived in for over 20 years. Therefore, the perceived level of social impact, in this case, was different from that of 'Bangkok Story Hostel'.

As a mixed qualitative and quantitative research, the qualitative aspect focused on general information on the AR-HB-hotel named 'Bangkok Story Hostel': building history, project background, location, the surrounding community, and building characteristics, while the quantitative aspect focused on analyzing data in such a way that we could numerically compare the results easily. 


\subsection{Result Guideline}

Nevertheless, the four main approaches: physical, economic, value, and social issues, used in this study can be a good general guideline for constructing a research procedure for other studies of AR-HB-hotels' changes and impacts. We could compare other types of AR-HB-hotels in terms of these approaches. For example, one case study at a Thonburi site had a high score of value perception and high score with respect to the physical issue but moderate score with respect to the economic issue and low score with respect to the social issue. In another case, a small AR-HB-hotel in a suburb area had high scores with respect to value perception and economic issues but moderate with respect to the physical issue and low with respect to the social issue. Hence, the results showed that a good economic return might not depend on the amount of investment alone. Good business management and focus on the intended target guests that match well with a particular project are very significant for business success.

In addition, AR-hotels that were not heritage buildings can also be studied this way. The four main approaches can be used to examine any old buildings turned into hotels with similar procedures. Comparatively, these AR-hotels might have low scores on value perception and social impact issues but high score on the level of physical changes and it might achieve a high score in economic changes.

No matter what they may be, the results from this kind of studies can make the hotel owner and other participants realized their situation more clearly. Most hotel owners may be a newcomer to the community that the hotel is located in. If there is not much negative social impact to the surrounding community, the owner can run their hotel business happily and proudly. On the other hand, if there are a lot of social impact issues to the community, the owner and stakeholders can examine what the causes are and make an effort to solve the problems such as participating with the community more and developing the environment of the community more, and so on. The hotel owner can compare the levels of physical and economic changes of his or her AR-hotel to those of other AR-hotels. Moreover, if the owner can add some values to the building, he or she can enhance his or her hotel business as well.

Referring to the introduction, this case study is a good representative of AR-HB hotels of which changes and impacts to the community were clear. However, the author thinks that other cases may differ markedly. For example, the case where the hotel owner was not fully cooperative may provide very different results. As another example, the case where there were hotels, more than one, in only one community was also not studied because the changes and impacts may not be clearly attributed to a particular one of these hotels.

\section{Conclusions and Recommendation}

For changes and impacts, this study focused on the physical, economic, and value changes, as well as social impacts of adaptive reuse of a heritage building, turned into a small hotel named 'Bangkok Story Hostel' in Bangkok, Thailand. We found that the level of physical, economic, and value changes rose up 1.20,0.80, and 1.71, respectively, from before the reuse while the level of social impact stayed the same or decreased very little from the level before the renovation (-0.05).

For generalization of the results, although this mixed qualitative and quantitative research may not be generalized wholly to another case with a significantly different context, but the four main approaches: physical, economic, value, and social issues, used in this study can be a good general guideline for constructing a research procedure for other studies of AR-HB-hotels' changes and impacts.

\section{Acknowledgements}

The author would like to express my sincere gratitude to Dr. Prapatpong Upala, Ajarn Pratana Kangsadal for their invaluable helps throughout my research and article writing. In addition, thank Mr. Sanpop Poolsuwan, Bangkok Story Hostel's owner, for the valuable cooperation. Additionally, I would like to thank the Faculty of Architecture, KMITL, National Research Council of Thailand (NRCT), National Institute of Development Administration (NIDA), and all of my peers in the Multi-disciplinary program for the shared inspiration and encouragement.

\section{References}

Altman, I. (1975). The Environment and Social Behavior: Privacy, Personal Space, Territory, Crowding. Brooks/Cole Pub. Co.

Architecture, $\quad$ Silpakorn $\quad$ University, $\quad$ NAJUA. https://www.tci-thaijo.org/index.php/NAJUA-Arch/article/view/45310

Avrami, E., Mason, R. \& Torre, M.D.L. (2000). Values and Heritage Conservation. The Getty Conservation Institute. Research Report. Los Angeles. Page 8.

Bynum, T. S., \& Purri, D. M. (1984). Crime and architectural style: An examination of the environmental design hypothesis. Criminal Justice and Behavior, 11(2), 179-196. 
Choochote, K. (2014). Factors affecting the selection of Boutique Hotel of tourist in Phuket Province. International Journal of Business and Management Study - IJBMS. 1(3). ISSN 2372 -3955

Dzhandzhugazova, E.A., Zaitseva, N.A., Larionova, A.A., Petrovskaya, M.V. \& Chaplyuk, V.Z. (2015). Methodological Aspects of Strategic Management of Financial Risks during Construction of Hotel Business Objects. Asian Social Science, 11(20), 229. doi:10.5539/ass.v11n20p229

Environmental Impacts of Tourism in Kermanshah (Iran). Asian Social Science, 6(11), 220-225. Retrieved from: http:/www.ccsenet.org/journal/index.php/ass/article/view/6675/6001

Giddings, B., Hopwood, B. \& O’Brien, G. (2002). Environment, economy and society: fitting them together into sustainable development. Sustainable Development, Sustainable Cities Research Institute, Newcastle upon Tyne, UK, Page 187-196. DOI: 10.1002/sd.199

Grey, William S. \& Liguori, Salvatore C. (2004). Hotel and Motel Management and Operations. Translated by Bangorn Chatrungroeng \& Worapol WattanaLeongarun. Pearson Education Indochina. ISBN 9749206894

ICOMOS (1994). The Nara Document on Authenticity. International Council on Monuments and Sites. Retrieved from https://www.icomos.org/charters/nara-e.pdf

Jeffery, C. R. (1971). Crime prevention through environmental design SAGE Publications.

Jeungsiriarrak, S. (2005). The Concepts of Architectural Conservation from the $18^{\prime \prime}$ to the End of the $20^{\circ}$ Century: From Sentiment and Faith to the Shared Heritage of Humankind. Journal of the Faculty of

Jokilehto, J., \& Feiden, B. M. (1998). Management Guildelines for World Cultural Heritage Site. ICCROM, Italy.

Jone, P. (2002). Introduction Hospitality Operations: An Indispensable guide to the industry (2nd ed.). Jennifer Pegg. London

Khanjanusthiti, P. (2009). Architectural Heritage and Community Conservation. Chulalongkorn Publishing. Bangkok.

Langston, C., Liu, C., Beynon, D., Jong, U. D., Langston, Y. L., Merlino, D., ... Williams, P. (2010). Strategic assessment of building adaptive reuse opportunities ARC Linkage Project LP0776579 Final report 2010. Mirvac School of Sustainable Dev. Retrieved from http://epublications.bond.edu.au/sustainable_development/141

Langston, C., Wong, F. K. W., Hui, E. C. M., \& Shen, L. (2008). Strategic assessment of building adaptive reuse opportunities in Hong Kong. Building and Environment, 43, 1709-1718. doi:10.1016/j.buildenv.2007.10.017

Lankford, S. V. \& Howard, D. R. (1994). Developing a Tourism Impact Attitude Scale. Journal of Travel Research. Volomn. 21, No. 1. https://doi.org/10.1177/004728759403200374

Ministerial Regulation. (2008). Determine the type and Criteria of Hotel Business. Ministry of Interior

Mohammadi, M., Khalifah, Z. \& Hosseini, H. (2010). Local People Perceptions toward Social, Economic and

Naseer, N. (2003). Planning for Urban Heritage Places: Reconciling Conservation, Tourism, and Sustainable Development. Journal of Literature, 17(4), 467-470. http://dx.doi.org/10.1177/0885412203251149.

National Statistical Office. (2014). The 2014 Hotels and Guest Houses Survey. Ministry of Information and Communication Technology. Retrieved from service.nso.go.th/nso/nsopublish/themes/files/questFullReport57.pdf

Pickard, Q. (2002). The Architects' Handbook. Oxford, United Kingdom: Blackwell Publishing. ISBN 0-632-03925-6

Policy Research for SMEs. (2004). Hotel Act. Macroeconomic strategies. Office of Small and Medium Enterprises Promotion (OSMEP). Bangkok.

Polnyotee, M., \& Thadaniti, S. (2015). Community-Based Tourism: A Strategy for Sustainable Tourism Development of Patong Beach, Phuket Island, Thailand. Asian Social Science, 11(27), 90. doi:10.5539/ass.v11n27p90

Pongsermpol, C. \& Upala, P. (2017). Impacts of Adaptive Reuse of Heritage Buildings to Small Hotel Buildings in Bangkok. Procedia - Social and Behavioral Sciences, 2, 449-458. http://dx.doi.org/10.21834/e-bpj.v2i5.621

Pongsermpol, C. (2011). Participants' Attitudes for Adaptive Reuse in Heritage Buildings for Thai Context. ICOMOS Thailand International Conference 2011, Phuket, Thailand. Proceedings Report. Page 217-227.

Pongsermpol, C. (2017). Association of Location and Accessibility of Small Adaptively Reused Hotels from Heritage Buildings in Bangkok with the hotels' rating. 12 ${ }^{\text {th }}$ Internation Conference of EASTS. 18-21 September, 2017. Ho Chi Minh City, Vietnam.

Remoy, H. \& Van Der Voordt, T. (2014). Adaptive reuse of office buildings into housing: opportunities and risks. Building Research \& Information, 42(3), 381-390. http://dx.doi.org/10.1080/09613218.2014.865922 
Somsawasdi, A. (2015). Small hotel business operation. Lifestyle Workshop for Small Hotel: Practical Scene for Efficient Result. Seminar. The Campus Room, Grand Hyatt Erawan Hotel, Bangkok, 7 October 2015.

Srisompong, S. (2004). Building Renovation for the Re-use. Journal of the Faculty of Archtecture King Mongkut's Institute of Technology Ladkrabang, $1(1), \quad 87 . \quad$ Retrieved from: https://www.tci-thaijo.org/index.php/archkmitl/article/view/4149/3603

Sthapitanonda, L. (2011). Building and facility design standards. Facility Management Office. Chulalongkorn University (Book in Thai).

Suksithi T., Pongsiri K. \& Kanchanapairote C. (2012). Guest's Expectation and Alternative Problem Solution of Boutique Hotel to Standardize Enhancement. Suan Sunandha Rajabhat University. Retrieved from http://ssruir.ssru.ac.th/handle/ssruir/769

Thirakomen, K. (2009). Basic Knowlegde: System Engineering. (Book in Thai) ISBN: 974-686-034-8

UNEP, U. N. (2003). Impacts of Tourism. United Nations Environment Programme. Retrieved December 6, 2016, Retrieved from http://www.unep.org/resourceefficiency/Business/SectoralActivities/Tourism/FactsandFigures aboutTourism/ImpactsofTourism/tabid/78774/Default.aspx

WHC, U. (2012). Operational Guidelines for the Implementation of the World Heritage Convention. Intergovernmental Committee for the Protection of the World Cultural and Nature. World Heritage Centre. UNESCO. Paris. Page 22

\section{Copyrights}

Copyright for this article is retained by the author(s), with first publication rights granted to the journal.

This is an open-access article distributed under the terms and conditions of the Creative Commons Attribution license (http://creativecommons.org/licenses/by/4.0/). 